\title{
Biodegradability and aquatic toxicity of new cleavable betainate cationic oligomeric surfactants
}

M. Teresa Garcia ${ }^{\mathrm{a} *}$, Isabel Ribosa ${ }^{\mathrm{a}}$, Iwona Kowalczyk ${ }^{\mathrm{b}}$, Marta Pakiet $^{\mathrm{b}}$, Bogumil Brycki $^{\mathrm{b}}$

aSurfactants and Nanobiotechnology Department, Institute of Advanced Chemistry of Catalonia, IQAC-CSIC, Jordi Girona 18-26, 08034, Barcelona, Spain.

M. Teresa Garcia, e-mail: teresa.garcia@iqac.csic.es

Isabel Ribosa, e-mail: isabel.ribosa@iqac.csic.es

bLaboratory of Microbiocides Chemistry, Faculty of Chemistry, Adam Mickiewicz University, Umultowska 89b, 61-614 Poznań, Poland.

Iwona Kowalczyk, e-mail: iwkow@amu.edu.pl

Marta Pakiet, e-mail: mpakiet@amu.edu.pl

Bogumil Brycki, e-mail: brycki@amu.edu.pl

*corresponding author. Phone: +34 9340061 00; fax: +34 932045904 .

e-mail address: teresa.garcia@iqac.csic.es

Keywords: cleavable surfactants; oligomeric surfactants; biodegradation; aquatic toxicity; Daphnia magna 


\section{ABSTRACT}

New cleavable oligomeric cationic surfactants containing ester groups susceptible to hydrolysis between the hydrocarbon tails and the hydrophilic moiety have been synthesized and their biodegradability and aquatic toxicity examined. Aerobic biodegradability was evaluated by applying a standard method for ready biodegradability, the $\mathrm{CO}_{2}$ Headspace test. Aquatic toxicity was assessed by means of the acute toxicity test with Daphnia. Cleavable oligomeric cationic surfactants undergo a significant biodegradation extent (31-52\%) as compared to dimeric surfactants without ester groups that showed null degradation in previous works. However, they do not attain the threshold of ultimate degradation required $(60 \%)$ to be classed as easily biodegradable chemicals. On the other hand, the introduction of cleavable groups in the surfactant hydrophobic chains reduces the toxic effects on the microorganisms responsible for degradation observed for conventional alkyl ammonium dimeric surfactants. Acute toxicity values of betainate cationic oligomeric surfactants to Daphnia magna, $\mathrm{IC}_{50}-48 \mathrm{~h}$, varies from 1.5 to $50 \mathrm{mg} / \mathrm{L}$. Aquatic toxicity of oligomeric cationic surfactants depends on their hydrophobicity and increases regularly with the alkyl chain length. However, whether the surfactant is a dimeric or a trimeric betaine ester does not affect their acute toxicity to crustacean. 


\section{Graphical Abstract}

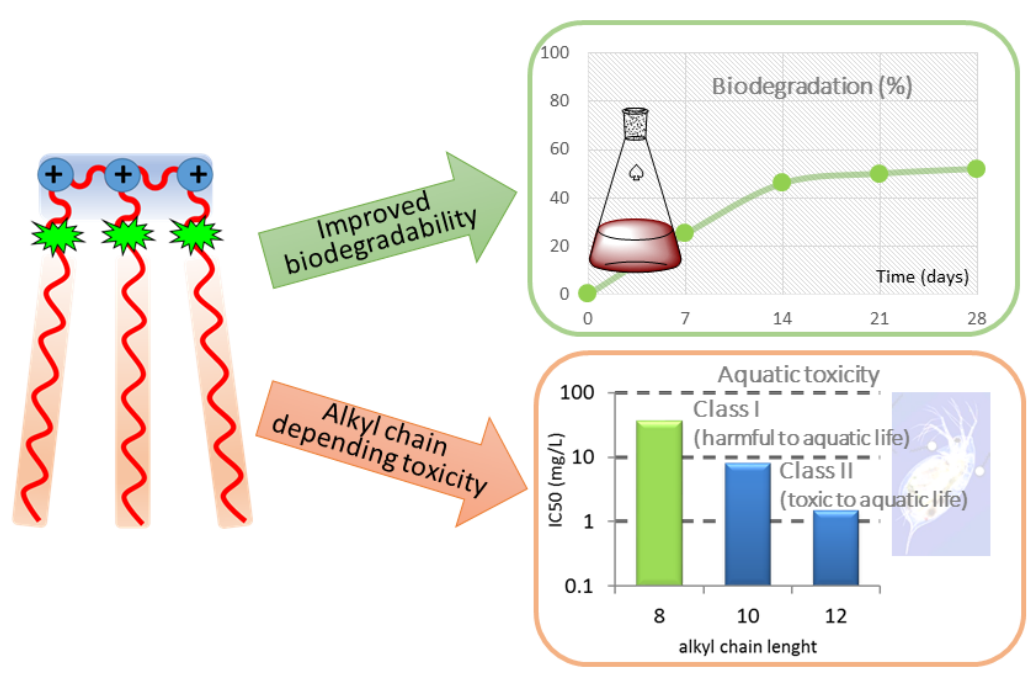

\section{HIGHLIGHTS}

- Cleavable cationic oligomeric surfactants with betaine ester bonds are synthetized

- Labile ester bonds enhance surfactant biodegradability by more than a $25 \%$

- Cleavable linkages reduces surfactant toxicity to aerobic microorganisms

- Incomplete surfactant degradation attributed to persistence of cationic moiety

- Aquatic toxicity depends on alkyl chain length of oligomeric surfactants 


\section{Introduction}

Surfactants have become an inseparable element of everyday human being life which is well evidenced by their large global production volumes as well as the multiplicity of applications of this special group of organic compounds $[1,2]$. Because of their emulsifying and dispersing properties, excellent antimicrobial activity and high efficacy as corrosion inhibitors cationic surfactants are widely used in household, biotechnology, pharmacy and other fields [3-5]. After use, surfactants are discharged to the environment through sewage after treatment or directly where no wastewater treatment system is available and part of them can get into the aquatic environment $[2,6-8]$. Surfactant degradation by microorganisms in wastewater treatment plants and aquatic ecosystems represents the main mechanism to assure low concentrations of these compounds in the environment and constitutes the major challenge in the design and production of safer molecules.

In recent years, oligomeric alkylammonium surfactants have attracted industry attention due to their unique properties and their relatively straightforward synthesis [9-12]. Oligomeric quaternary ammonium salts are novel cationic surface-active agents formed by two or more monomeric surfactant units with the cationic head groups linked by a spacer. Dimeric quaternary ammonium salts exhibit much better surface, interfacial, antimicrobial and anticorrosive properties than the corresponding monomeric cationic surfactants $[11,13,14]$ which means that the same surface or biocidal effects can be attained using lower surfactant amounts. The increasing use of dimeric surfactants may result in an increment of their concentration in aquatic compartments making necessary the assessment of their biodegradation. Nevertheless, in spite of the extensive research on these surfactants, few data are available about their environmental properties [15]. Some previous studies of the authors 
demonstrate that gemini quaternary ammonium salts are very efficient compounds in comparison to the corresponding monomeric surfactants $[16,17]$ but show null biodegradation in standard tests for ready biodegradability $[15,17]$. Resistance to biodegradation was partially blamed for the toxicity of gemini surfactants to aerobic microbial population involved in the degradation processes [15]. Furthermore, monomeric and dimeric alkylammonium salts are not only poor biodegradable compounds but can also be harmful to water organisms such as algae and daphnids $[15,17,18]$.

Concern about environmental protection becomes the major driving force in the synthesis of novel oligomeric surfactants with better ecotoxicological profiles. A useful approach to increase environmental safety of monomeric cationic surfactants is to develop cleavable compounds by introducing a labile linker between the hydrophobic tail and the hydrophilic part. This type of strategy was successfully applied in the replacement of monocatenary dodecyltrimethylammonium chloride by more degradable quaternary ammonium estercontaining salts [19]. Therefore, a good approach to increase the environmental safety of oligomeric cationic surfactants could be to synthesize new ester derivatives surfactants which in principle should show improved biodegradability [20-23]. In addition, gemini surfactants containing quaternary nitrogen atoms and heteroatoms $(\mathrm{N}, \mathrm{O})$ have potential applications as foam stabilizers [24], fabric softeners [25], detergents [26], solubilizing agents [27], biological active compounds [28], antimicrobial agents [29,30] and corrosion inhibitors [31]. The aim of the present work is to develop a series of new cationic oligomeric surfactants with enhanced biodegradability through the synthesis of cleavable quaternary ammonium salts containing a labile ester bond between the hydrophobic tails and the hydrophilic moiety. Long alkyl betainate cationic dimeric and trimeric surfactants with an aza-substituted spacer are synthetized for the first time. They are examined for their biodegradability and aquatic 
toxicity and hence the effect of introducing labile ester groups on their ecological properties is investigated.

This study contributes to the knowledge of structural parameters affecting the fate and effects of cleavable cationic surfactants in the aquatic environment and can be useful in the development of efficient and environmentally friendly oligomeric surface-active agents.

\section{Materials and methods}

\subsection{General information}

Starting materials: $\quad N, N, N^{\prime}, N^{\prime \prime}, N^{\prime \prime}$-Pentamethyldiethylenetriamine (99\%, Merck), chloroacetic acid (Merck, $\geq 99.0 \%$ ), 1 - octanol (EMD Millipore, Merck), 1 - decanol ( $\geq 98 \%$ Merck), 1-dodecanol (EMD Millipore, Merck). All ${ }^{1} \mathrm{H}$ and ${ }^{13} \mathrm{C}$ NMR spectra were obtained with a Spectrometer NMR Varian Mercury $400 \mathrm{MHz}$ in $\mathrm{CDCl}_{3}$ or $\mathrm{D}_{2} \mathrm{O}$ in reference to TMS. Infrared spectra were recorded in a Jasco FT-IR spectrometer type ATR 4700 in the range of 4000-400 $\mathrm{cm}^{-1}$. The ESI mass spectra and elemental analysis were recorded on a Waters/Micromass-ZQ mass spectrometer.

\subsection{Materials}

New cationic betainate dimeric and trimeric surfactants having an aza-substituted spacer group and different alkyl chain lengths have been synthesized and characterized. Fig. 1 displays the molecular structure of the herein synthesized cationic oligomeric surfactants. 

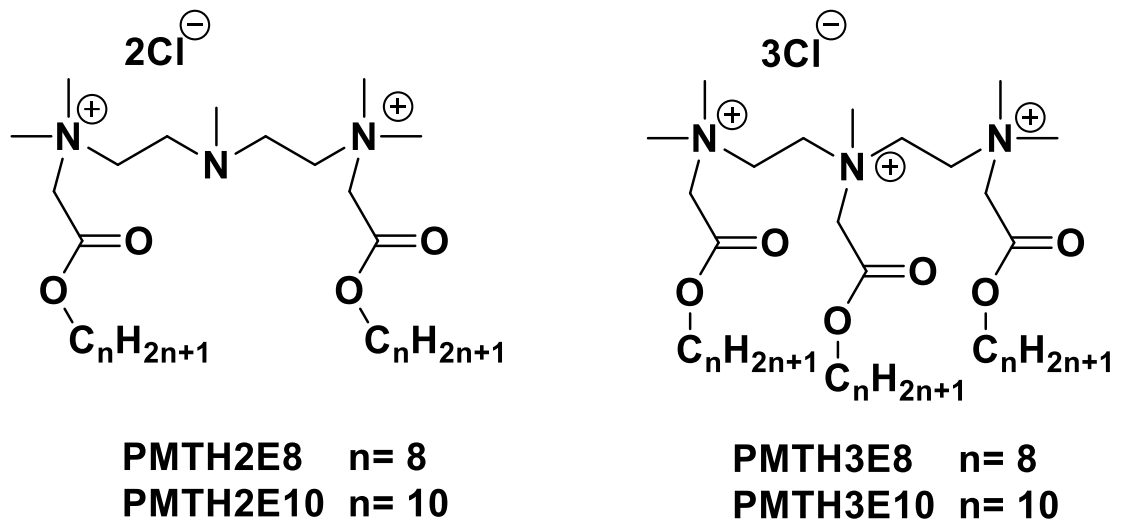

$$
\begin{array}{ll}
\text { PMTH3E8 } & n=8 \\
\text { PMTH3E10 } & n=10 \\
\text { PMTH3E12 } & n=12
\end{array}
$$

Fig. 1. Structure of the gemini (PMTH2E8 and PMTH2E10) and trimeric surfactants (PMTH3E8, PMTH3E10 and PMTH3E12)

\subsubsection{Synthesis of chloroesters}

Octyl 2-chloroacetate. To chloroacetic acid (25 g, 0.27 mol) was added 1-octanol (35 g, $0.27 \mathrm{~mol}$ ) and $6 \mathrm{ml}$ of concentrated sulfuric acid. The reaction mixture was stirred at $60{ }^{\circ} \mathrm{C}$ for 13h. After cooling, the mixture was diluted with $15 \mathrm{ml}$ of diethyl ether. The organic layer was washed successively with water $(3 \times 20 \mathrm{ml})$, saturated aqueous sodium carbonate $(2 \times 25 \mathrm{ml})$ and water $(2 \times 20 \mathrm{ml})$. The separated ethereal layer was dried over anhydrous sodium sulfate. The organic solvent was removed under reduced pressure.

Decyl 2-chloroacetate. To chloroacetic acid (25 g, 0.27 mol), 1-decanol (43 g, 0.27 mol) and $6 \mathrm{ml}$ of concentrated sulfuric acid were added. The reaction mixture was stirred at $60{ }^{\circ} \mathrm{C}$ for $13 \mathrm{~h}$. To get the final product analogous procedure to that described for octyl 2-chloroacetate was applied.

Dodecyl 2-chloroacetate. To a round bottomed flask containing chloroacetic acid (25 g, $0.27 \mathrm{~mol}$ ) was added 1-dodecanol (50 g, $0.27 \mathrm{~mol}$ in $15 \mathrm{ml}$ of toluene) and $6 \mathrm{ml}$ of concentrated sulfuric acid. The reaction mixture was stirred at $60{ }^{\circ} \mathrm{C}$ for $13 \mathrm{~h}$. The final product was obtained by applying the previously described procedure. 


\subsubsection{Betainate gemini surfactants}

PMTH2E8.N,N'-((methylazanediyl)bis(ethane-2,1-diyl))bis( $N, N$-dimethyl-2-

(octyloxy)-2-oxoethan-1-aminium) chloride (octylbetainate gemini). Yield: 85\%; white solid; mp: $173-175{ }^{\circ} \mathrm{C} ;{ }^{1} \mathrm{H}$ NMR $\left(400 \mathrm{MHz}, \mathrm{D}_{2} \mathrm{O}\right) \delta / \mathrm{ppm} 0.86(\mathrm{t}, 6 \mathrm{H}), 1.27-1.36(\mathrm{~m}, 24 \mathrm{H}), 1.72(\mathrm{t}$, $4 \mathrm{H}), 2.41(\mathrm{~s}, 3 \mathrm{H}), 2.86-2.94(\mathrm{~m}, 4 \mathrm{H}), 3.20(\mathrm{~s}, 12 \mathrm{H}), 3.49(\mathrm{t}, 4 \mathrm{H}), 3.99(\mathrm{t}, 4 \mathrm{H}), 4.31(\mathrm{~s}, 4 \mathrm{H}){ }^{13} \mathrm{C}$

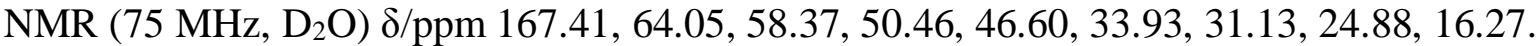
ESI-MS m/z $258 \mathrm{C}_{29} \mathrm{H}_{61} \mathrm{~N}_{3} \mathrm{O}_{4}{ }^{2+}(100 \%)$. ATR-IR 3025, 2918, 1737, 1478, 1242, 915cm $\mathrm{cm}^{-1}$ PMTH2E10.N,N'-((methylazanediyl)bis(ethane-2,1-diyl))bis(N,N-dimethyl-2(decyloxy)-2-oxoethan-1-aminium) chloride (decylbetainate gemini). Yield: 86\%; white solid; mp: $220-222{ }^{\circ} \mathrm{C} ;{ }^{1} \mathrm{H}$ NMR $\left(400 \mathrm{MHz}, \mathrm{D}_{2} \mathrm{O}\right): \delta / \mathrm{ppm} 0.87(\mathrm{t}, 6 \mathrm{H}), 1.24-1.30(\mathrm{~m}, 28 \mathrm{H}), 1.72(\mathrm{t}$, $4 \mathrm{H}), 2.41(\mathrm{~s}, 3 \mathrm{H}), 2.84-2.90(\mathrm{~m}, 4 \mathrm{H}), 3.22(\mathrm{~s}, 12 \mathrm{H}), 3.41(\mathrm{t}, 4 \mathrm{H}), 4.01(\mathrm{t}, 4 \mathrm{H}), 4.31(\mathrm{~s}, 4 \mathrm{H}){ }^{13} \mathrm{C}$ NMR (75 MHz, $\left.\mathrm{D}_{2} \mathrm{O}\right): \delta / p p m ~ 167.65,70.76,58.34,58.02,57.48,56.17,33.86,31.47,31.11$, 31.06, 30.33, 27.77, 24.81, 16.21. ESI-MS (m/z) $285 \mathrm{C}_{33} \mathrm{H}_{69} \mathrm{~N}_{3} \mathrm{O}_{4}{ }^{2+}(100 \%)$ ATR-IR 3010, $2926,1752,1486,1227,929 \mathrm{~cm}^{-1}$

General procedure for betainate dimeric surfactants: To a solution of $N, N, N{ }^{\prime}, N{ }^{\prime \prime}, N$ ”' pentamethyldietylenetriamine $(0.0058 \mathrm{~mol})$ in acetonitrile $(5 \mathrm{~mL})$ were added $0.012 \mathrm{~mol}$ of octyl 2-chloroacetate or decyl 2-chloroacetate. The reaction mixture was refluxed for 60 hours. After cooling down, the solvent was evaporated under reduced pressure. The crude product was crystallized from acetonitrile/diethyl ether (2:1) mixture.

\subsubsection{Betainate trimeric surfactants}

PMTH3E8. $N^{1}-\left(2-\left(\right.\right.$ dimethyl(2-(octyloxy)-2-oxoethyl)ammonio)ethyl)- $N^{1}, N^{2}, N^{2}-$ trimethyl- $N^{1}, N^{2}$-bis(2-(octyloxy)-2-oxoethyl)ethane-1,2-diaminium (octyl betainate trimeric). 
Yield: 89\%; white solid; mp: $197-200{ }^{\circ} \mathrm{C} ;{ }^{1} \mathrm{H}$ NMR (400 MHz, $\mathrm{D}_{2} \mathrm{O}$ ): $\delta / \mathrm{ppm} 0.88$ (t, 9H), $1.28-1.39(\mathrm{~m}, 36 \mathrm{H}), 1.71(\mathrm{t}, 6 \mathrm{H}), 3.43(\mathrm{~s}, 15 \mathrm{H}), 3.58(\mathrm{~s}, 8 \mathrm{H}), 4.07(\mathrm{t}, 6 \mathrm{H}), 4.31(\mathrm{~s}, 6 \mathrm{H}){ }^{13} \mathrm{C}$ NMR (75 MHz, D $2 \mathrm{O}): \delta / p p m ~ 167.62,70.77,58.04,57.48,51.50,51.21,50.92,50.64,50.35$, 33.93, 31.19, 31.13, 30.38, 27.83, 24.88, 16.27. ESI-MS (m/z) $228 \mathrm{C}_{39} \mathrm{H}_{80} \mathrm{~N}_{3} \mathrm{O}_{6}{ }^{3+}(100 \%)$ ATR-IR 3025, 2918, 1729, 1486, 1234, 922 $\mathrm{cm}^{-1}$

PMTH3E10. $N^{1}$-(2-(dimethyl(2-(decyloxy)-2-oxoethyl)ammonio)ethyl)- $N^{1}, N^{2}, N^{2}$ trimethyl- $N^{1}, N^{2}$-bis(2-(decyloxy)-2-oxoethyl)ethane-1,2-diaminium(decylbetainate trimeric). Yield: 90\%; white solid; mp: $187-190{ }^{\circ} \mathrm{C} ;{ }^{1} \mathrm{H}$ NMR (400 MHz, $\left.\mathrm{D}_{2} \mathrm{O}\right): \delta / \mathrm{ppm} 0.85$ (t, 9H), $1.22-1.39(\mathrm{~m}, 42 \mathrm{H}), 1.70(\mathrm{t}, 6 \mathrm{H}), 3.41(\mathrm{~s}, 15 \mathrm{H}), 3.56(\mathrm{~s}, 8 \mathrm{H}), 3.99(\mathrm{t}, 6 \mathrm{H}), 4.31(\mathrm{~s}, 6 \mathrm{H}){ }^{13} \mathrm{C}$


24.50, 15.90.ESI-MS (m/z) $256 \mathrm{C}_{45} \mathrm{H}_{92} \mathrm{~N}_{3} \mathrm{O}_{6}{ }^{3+}$ (70\%)ATR-IR 3017, 2926, 1745, 1486, 1219 , $937 \mathrm{~cm}^{-1}$

PMTH3E12. $N^{1}-\left(2-\left(\right.\right.$ dimethyl(2-(dodecyloxy)-2-oxoethyl)ammonio)ethyl)- $N^{l}, N^{2}, N^{2}$ trimethyl- $N^{1}, N^{2}$-bis(2-(dodecyloxy)-2-oxoethyl)ethane-1,2-diaminium(dodecyl betainate trimeric). Yield: $85 \%$; white solid; mp: $195-197{ }^{\circ} \mathrm{C} ;{ }^{1} \mathrm{H}$ NMR (400 MHz, $\mathrm{CDCl}_{3}$ ): $\delta / \mathrm{ppm} 0.86$ (t, 9H), 1.26-1.39 (m, 48H), $1.62(\mathrm{t}, 6 \mathrm{H}), 3.67(\mathrm{~s}, 15 \mathrm{H}), 3.61(\mathrm{~s}, 8 \mathrm{H}), 4.15(\mathrm{t}, 6 \mathrm{H}), 4.86(\mathrm{~s}, 6 \mathrm{H})$ ${ }^{13} \mathrm{C}$ NMR $\left(75 \mathrm{MHz}, \mathrm{CDCl}_{3}\right): \delta / \mathrm{ppm} 164.83,66.72,62.99,61.81,61.60,57.18,52.08,50.70$, $48.58,45.11,42.48,32.74,31.82,29.39,29.10,28.52,25.81,14.03$. ESI-MS (m/z) 285 $\mathrm{C}_{51} \mathrm{H}_{104} \mathrm{~N}_{3} \mathrm{O}_{6}{ }^{3+}(100 \%)$ ATR-IR 3017, 2910, 1752, 1486, 1203, $975 \mathrm{~cm}^{-1}$.

General procedure for betainate trimeric surfactants: To a solution of $N, N, N{ }^{\prime}, N{ }^{\prime}, N^{\prime \prime}-$ Pentamethyldietylenetriamine $(0.0058 \mathrm{~mol})$ in acetonitrile $(5 \mathrm{~mL})$ was added $0.0174 \mathrm{~mol}$ of the appropriate chloroester. The reaction mixture was refluxed for 60 hours. After cooling down, the crude product was filtered and crystallized from acetonitrile/diethyl ether (2:1) mixture to give a white solid. 


\subsection{Biodegradation test}

The aerobic biodegradability of the cleavable oligomeric cationic surfactants was assessed by applying the $\mathrm{CO}_{2}$ headspace test (OECD 310) [32]. This standard method evaluates the ultimate biodegradability of an organic compound in aqueous solution by analysis of the inorganic carbon $\left(\mathrm{CO}_{2}\right.$ production). The biodegradation kinetics of the oligomeric surfactants investigated were determined by measuring periodically the $\mathrm{CO}_{2}$ production resulting from the breakdown of the surfactant molecules by microbial population. Each cationic surfactant, as the sole source of carbon and energy, was added at $15 \mathrm{mg} \mathrm{C} / \mathrm{L}$ to a buffered-aqueous medium (pH 7.4 \pm 0.2 ). Sodium n-dodecyl sulfate (SDS) at $20 \mathrm{mg} \mathrm{C/L}$ was employed as reference substance. The solutions, inoculated with activated sludge collected from a wastewater treatment plant (Manresa, Barcelona), were incubated in sealed vessels at $20{ }^{\circ} \mathrm{C}$. Weekly sampling was performed for measuring the increase in the inorganic carbon concentration during incubation. The tests ran for 28 days. For each of the surfactants investigated, inhibition tests with binary mixtures of SDS and oligomeric surfactant at 20 and $15 \mathrm{mg} \mathrm{C} / \mathrm{L}$, respectively, were also carried out. Biodegradation was assessed by measuring the net increase in the concentration of inorganic carbon, i.e., the difference between the $\mathrm{CO}_{2}$ production in the vessels containing surfactant and the $\mathrm{CO}_{2}$ endogenous production, determined using a carbon analyzer (Shimadzu TOC-5050). The biodegradation extent was expressed as a fraction of the theoretical amount of inorganic carbon based on the initial concentration of the test compound. The pass level for this method is stablished in $60 \%$, thus a compound exceeding this biodegradation threshold is regarded as readily biodegradable. 


\subsection{Aquatic toxicity test}

Daphnia magna acute immobilization tests [33] were performed to evaluate the adverse effects of the surfactants synthesized to aquatic biota. This standard bioassay is one of the most widely used for the aquatic toxicity analysis of chemicals due to the broad distribution of daphnids in a wide range of habitats and their relatively short life cycle.

Freshwater crustacean, laboratory bred and less than $24 \mathrm{~h}$ old, were employed to perform the assay, where the criterion for effect measurement was the swimming incapability, i.e., the immobility of the test organism within $15 \mathrm{~s}$ after gentle agitation. The $\mathrm{pH}$ of the medium was 8.0 and the total hardness was $250 \mathrm{mg} / \mathrm{L}$ (as $\mathrm{CaCO}_{3}$ ), with a $\mathrm{Ca} / \mathrm{Mg}$ ratio of $4 / 1$. Tests were performed in the dark at $20{ }^{\circ} \mathrm{C}$. For each compound, ten concentrations in a geometric series were tested. Twenty daphnia, divided into four batches of five animals each, were used at each test concentration. The immobility percentage at $48 \mathrm{~h}$ was plotted against concentration on probability-logarithmic scale. Probit analysis conducted by means of the SPSS statistics software package (IBM SPSS Statistics) was employed as the statistical procedure to estimate the concentration to immobilize $50 \%$ of the daphnia after the exposure period $\left(\mathrm{IC}_{50}\right)$ and the confidence limits $(\mathrm{p}=0.95)$.

\section{Results and discussion}

\subsection{Biodegradability under aerobic conditions}

Biodegradation of dimeric and trimeric betaine ester surfactants was evaluated by applying the $\mathrm{CO}_{2}$ Headspace Test [32], reference method approved by the European Commission to evaluate surfactant biodegradation. The $\mathrm{CO}_{2}$ production evolved from the mineralization of the 
oligomeric surfactants was determined by measuring the inorganic carbon generated in the test vessels in excess to that generated in blank vessels. The biodegradation was expressed as a percentage of the theoretical maximum inorganic carbon production, based on the initial amount of surfactant added. Table 1 shows the mineralization percentages obtained for the ester-containing surfactants, the 28-day biodegradation mean include the $95 \%$ confidence interval.

\section{Table 1.}

Biodegradation percentages of gemini (PMTH2E8 and PMTH2E10) and trimeric (PMTH3E8, PMTH3E10 and PMTH3E12) surfactants, and the reference substance, sodium dodecyl sulfate (SDS) (95\% confidence limits over 28 days based on 4 replicates).

\begin{tabular}{lcccc}
\hline Compound & \multicolumn{4}{c}{ Biodegradation (\%) } \\
\cline { 2 - 5 } & 7 days & 14 days & 21 days & 28 days \\
\hline SDS & 78 & 98 & 99 & $99 \pm 2.2$ \\
PMTH2E8 & 17 & 26 & 27 & $31 \pm 1.2$ \\
PMTH2E10 & 20 & 31 & 33 & $39 \pm 4.3$ \\
PMTH3E8 & 25 & 37 & 36 & $41 \pm 2.3$ \\
PMTH3E10 & 22 & 42 & 41 & $42 \pm 0.9$ \\
PMTH3E12 & 20 & 46 & 48 & $52 \pm 1.7$ \\
\hline
\end{tabular}

Dimeric and trimeric surfactants investigated undergo a substantial degree of mineralization (31-52\%) under test conditions over the 28 day-period. Although none of them reaches the level of biodegradation necessary to be considered as readily biodegradable, i.e., $>60 \%$, significant percentages of biodegradation are attained compared to gemini surfactants without ester groups, which show null biodegradation under the same conditions $[15,17]$. For both type of oligomeric betaine ester surfactants (dimeric and trimeric), biodegradation increases with lengthening of the alkyl chain (Fig. 1). 


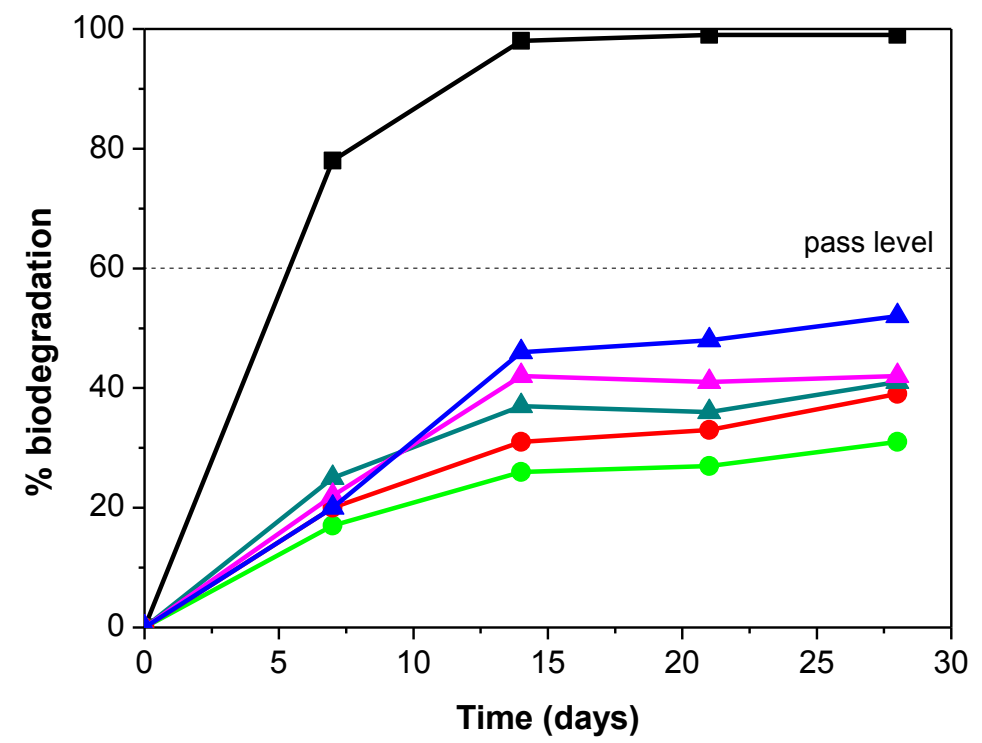

Fig. 1. Biodegradation curves for oligomeric cationic surfactants: PMTH2E8 (๑);


substance SDS ( $\boldsymbol{\square})$. Dotted line indicates the pass level for ready biodegradability (60\% of theoretical $\mathrm{CO}_{2}$ production) for the biodegradation test conducted.

Furthermore, the percentage of biotransformation is superior for trimeric surfactants than for dimeric ones (Fig. 2), meaning that the presence of an alkyl propionate substituent attached to the nitrogen atom in the spacer raises the biodegradation extent. Thus, the surfactant containing three ester groups and the longest carbon chain, PMTH3E12, is the compound undergoing the highest biodegradation percentage (52\%) (Table 2).

The biodegradation percentages found in this study for betainate dimeric surfactants with an aza-substituted spacer are in line with the values reported in the literature for other cationic ester-containing gemini surfactants [1]. Thus, our results are in good agreement with those observed for dodecyl betaine ester dimeric surfactant having a two-carbon spacer unit and esterquat dimeric surfactants with decyl or dodecyl chains and a three- or six-carbon spacer unit (40-54\% biodegradation) $[19,24]$. Likewise, the results are similar to those found 
for decyl, dodecyl and tetradecyl esterquat dimeric surfactants with a 2-hydroxypropyl spacer (50-59\% biodegradation) [34] and dodecyl esterquat dimeric surfactants with either saturated or unsaturated four-carbon spacer (45-58\% biodegradation) [35].

When comparing the biodegradation results for oligomeric betainate surfactants here studied (Table 1) with those described for monomeric ester-containing surfactants [19,34], the monomeric surfactants attain biodegradation percentages $\geq 80 \%$ whereas the oligomeric ones do not reach $60 \%$ of ultimate degradation at 28 days. Unlike cationic ester monomeric surfactants, the betainate oligomeric surfactants investigated cannot be considered as readily biodegradable.

Biodegradation curves of oligomeric surfactants investigated (Fig. 2) indicate they undergo a partial oxidation since the curves level off at degradation percentages lower than $60 \%$. The envisaged hydrolysis of ester linkages of dimeric and trimeric surfactants yields fatty alcohols and hydrophilic dicationic or tricationic moieties. Since the fatty alcohols degrade rapidly (first they are oxidized to fatty acids and then broken down by the $\beta$-oxidation process) [19], the plateaus observed after two weeks (Fig. 2) suggest a practically total mineralization of the long alkyl chains and a likely poor mineralization of dicationic and tricationic species. Resistance to microbial degradation of dicationic hydrolysis compounds was proven [19] by synthetizing and testing for biodegradability $N-N^{\prime}$-bis (2-carboxymethyl)- $N, N, N^{\prime}, N^{\prime}$-tetramethyl-1,2-ethane ammonium dibromide, which can be generated from biochemical hydrolysis of a betaine ester gemini, and $N-N^{\prime}$-bis (2-hydroxyethyl)$N, N, N^{\prime}, N^{\prime}$-tetramethyl-1,3-propanediammonium dibromide, which can be produced from an esterquat gemini. By applying the Closed Bottle test, a poor degradation $(<20 \%)$ for both hydrophilic species was found. This approach to the biodegradation process of cleavable amphiphiles would satisfactorily explain the results herein obtained for betainate oligomeric surfactants. The rapid biodegradation of the tails and the scarce mineralization of polycationic 
moieties after the hydrolysis of betainate oligomeric surfactants would justify the greater degradation percentage of trimeric respect to gemini surfactants as well as a higher biodegradation extent with elongation of the alkyl chain. In fact, the biodegradation percentages obtained for the ester-containing oligomeric surfactants studied are consistent with the relative weight of the fatty alcohols in each surfactant molecule, which are 38 and 44\% for dimeric PMTH2E8 and PMTH2E10 and 43, 48 and 53\% for PMTH3E8, PMTH3E10 and PMTH3E12, respectively.

In the present study, the spacer chain contains a tertiary nitrogen atom for betainate gemini surfactants or a quaternary nitrogen atom for betainate trimeric surfactants that can significantly affect the biocidal properties of the surfactant. Since cationic monomeric and gemini surfactants are commonly known as antimicrobial agents [36], the biological activity of alkylammonium salts can have a negative influence on their biodegradation. Therefore, the biodegradation data should be interpreted bearing in mind that many quaternary ammonium salts can inhibit the growth of microorganisms which cause degradation of surfactants $[15,37,38]$.

In addition, the biodegradation test enabled us to evaluate potential inhibitory effects of the investigated oligomeric surfactants on microbial consortia involved in the biodegradation process. The toxicity of the cleavable cationic oligomeric surfactants to the aerobic microorganisms was evaluated by determining the biodegradation inhibition of the reference substance (SDS) in binary mixtures of the test surfactant and the reference compound (Table 2). 


\section{Table 2.}

Inhibition of the reference substance (SDS) biodegradation by the gemini (PMTH2E8 and PMTH2E10) and trimeric (PMTH3E8, PMTH3E10 and PMTH3E12) surfactants.

\begin{tabular}{ccc}
\hline \multicolumn{1}{c}{ Compounds } & Concentration $(\mathrm{mg}$ C/L) & Inhibition (\%) \\
\hline SDS+ PMTH2E8 & $20+15$ & 0 \\
SDS+ PMTH2E10 & $20+15$ & 0 \\
SDS+ PMTH3E8 & $20+15$ & 0 \\
SDS+ PMTH3E10 & $20+15$ & 0 \\
SDS+ PMTH3E12 & $20+15$ & 0 \\
\hline
\end{tabular}

None of the oligomeric betainate ester surfactants tested inhibited the inoculum activity under the biodegradation test conditions (Table 2). These results indicate that these cationic cleavable surfactants are non-toxic to the bacterial inoculum in the experimental conditions of the biodegradability testing. This is an outstanding finding since significant inhibitory effects $(37-71 \%)$ were found by the authors for structurally related dimeric surfactants without ester groups [15]. The incorporation of ester bonds into the lipophilic chains of the oligomeric surfactants leads to a total reduction of their antimicrobial activity against the microorganisms responsible for biodegradation (likely due to the chemical or enzymatic hydrolysis of the cleavable surfactants and further degradation of the released fatty alcohols). Therefore, the incomplete degradation of the betainate oligomeric surfactants can be attributed to the low amenability to biological oxidation of the hydrophilic cationic species generated from the hydrolysis of surfactants and not to their inhibitory effects on aerobic microbial consortia. 


\subsection{Aquatic toxicity}

To assess the aquatic toxicity of oligomeric ester-containing cationic surfactants the acute toxicity to Daphnia magna was evaluated. This planktonic crustacean was selected as model organism since it is very sensitive to pollution and broadly employed to estimate surfactant toxicity [39-41]. Toxic effects of the surfactants on Daphnia magna were determined taken as effect criterion the immobility of these daphnids after 24 and $48 \mathrm{~h}$ exposure at increasing surfactant concentrations. Fig. 3 shows the plot of immobilization as a function of concentration for the PMTH3E10 as example whereas Table 3 displays the values for Daphnia magna immobilization test for all the investigated cationic surfactants. The effective concentration to immobilize half of the crustacean population at $48 \mathrm{~h}\left(\mathrm{IC}_{50}\right)$ was 7.5 and 50 $\mathrm{mg} / \mathrm{L}$ for cationic dimeric surfactants with alkyl chain lengths of 10 and 8 carbon atoms, respectively, and ranged from 1.5 to $37 \mathrm{mg} / \mathrm{L}$ for trimeric surfactants with alkyl chains from 12 to 8 carbon atoms (Table 3 ).

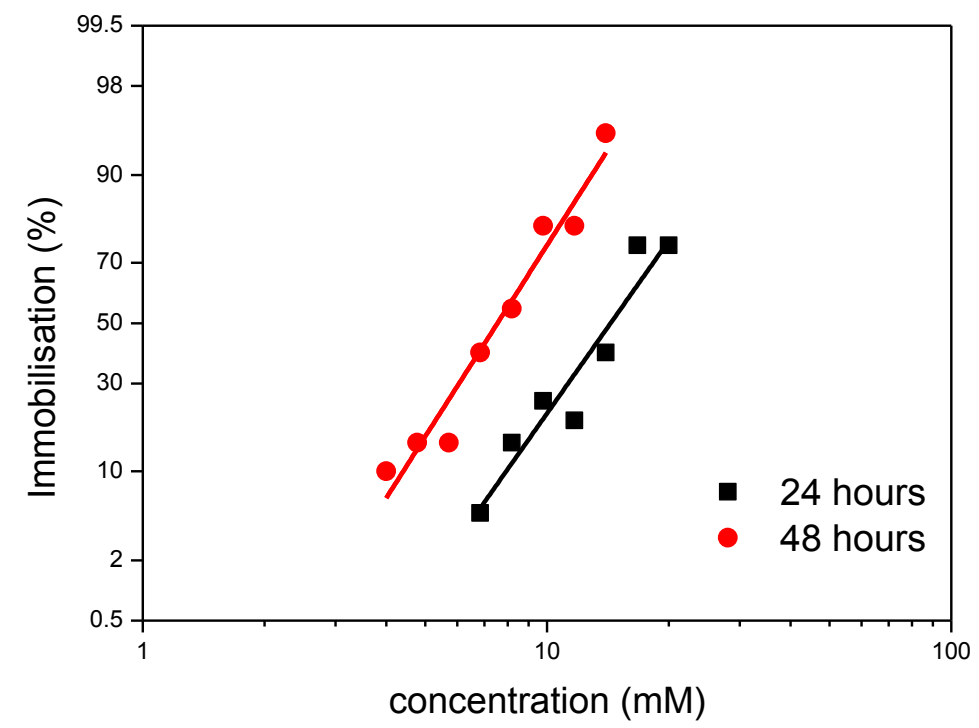

Fig. 3. Immobilisation percentage of daphnia after 24 and $48 \mathrm{~h}$ as a function of the surfactant concentration for PMTH3E10. 


\section{Table 3.}

Daphnia magna acute toxicity after $48 \mathrm{~h}$ exposure time ( $\left.\mathrm{IC}_{50}\right)$ with $95 \%$ confidence limits for dimeric (PMTH2E8 and PMTH2E10) and trimeric (PMTH3E8, PMTH3E10 and PMTH3E12) surfactants.

\begin{tabular}{ll}
\hline Surfactants & $\mathrm{IC}_{50}(95 \% \mathrm{CI})(\mathrm{mg} / \mathrm{L})$ \\
\hline PMTH2E8 & $50(42-61)$ \\
PMTH2E10 & $7.5(6.8-8.2)$ \\
PMTH3E8 & $37(32-42)$ \\
PMTH3E10 & $8.1(7.3-8.9)$ \\
PMTH3E12 & $1.5(1.3-1.9)$ \\
\hline
\end{tabular}

It can be observed that for betainate dimeric and trimeric surfactants, aquatic toxicity largely increases with increasing the length of the alkyl chains of the surfactant. A good linear relationship can be established between the $\log \mathrm{IC}_{50}$ value and the number of carbon atoms in the hydrophobic chains (Fig. 4).

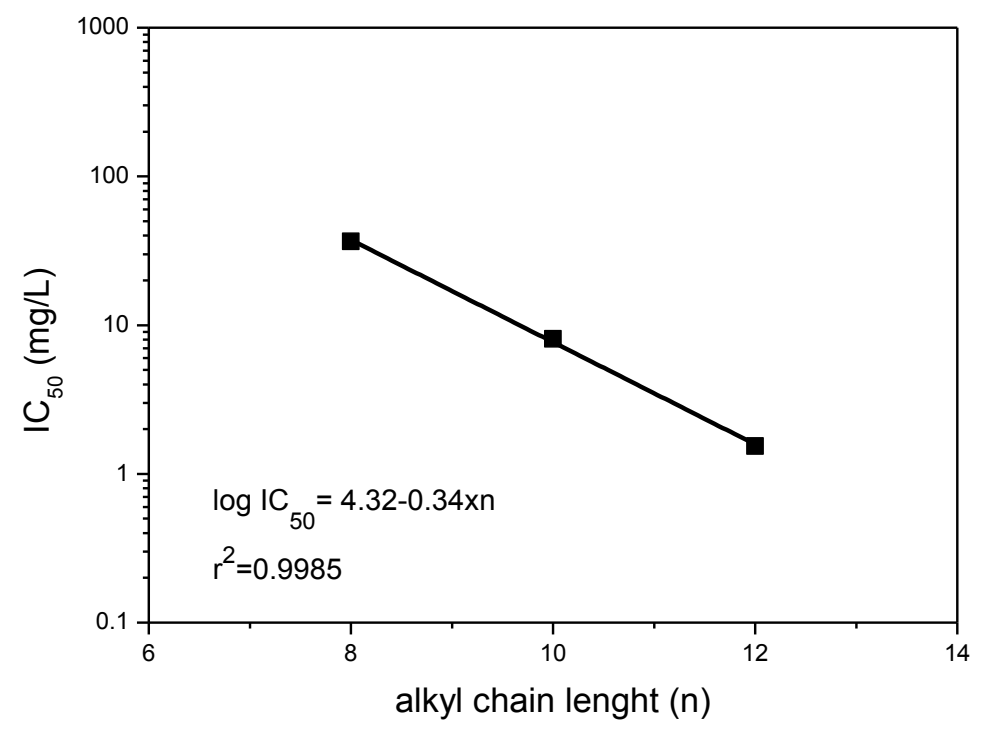

Fig. 4. Aquatic toxicity for trimeric surfactants, PMTH3En, as a function of the alkyl chain length (n). 
Aquatic toxicity sharply increases with the elongation of the alkyl chains attached to the polar head group through an ester bond. Therefore, hydrophobicity of the betainate oligomeric surfactants determined by the alkyl chain length plays a major role in their aquatic toxicity. On the other hand, the nature of the surfactant, dimeric or trimeric, does not exert a significant effect on their toxicity to crustacean as similar toxicity values were found for both types of oligomeric surfactants at the same alkyl chain length. Taking into account the toxicity results obtained and the Ecotoxicity Hazard categories defined in the OECD Guidelines [42], oligomeric surfactants here investigated can be classified as a function of its alkyl chain length as follows. Cationic betaine ester-containing surfactants with alkyl chain lengths $\geq 10$ $\mathrm{C}$ are categorized as "Toxic to aquatic life" $\left(1<\mathrm{IC}_{50} \leq 10 \mathrm{mg} / \mathrm{L}\right.$, Acute toxicity II) whereas surfactants with alkyl chains $<10 \mathrm{C}$ are classed as "Harmful to aquatic life" $\left(10<\mathrm{IC}_{50} \leq 100\right.$ $\mathrm{mg} / \mathrm{L}$, Acute toxicity III).

Comparing with conventional alkylammonium gemini surfactants, the $\mathrm{IC}_{50}$ value obtained for dodecyl betainate trimeric surfactant PMTH3E12, $1.5 \mathrm{mg} / \mathrm{L}$, is greater than those reported [15] for dodecyl gemini surfactants $\left(\mathrm{IC}_{50}<1 \mathrm{mg} / \mathrm{L}\right)$ either with a flexible hexamethylene spacer, $0.63 \mathrm{mg} / \mathrm{L}$, or a rigid $p$-xylyl spacer, $0.73 \mathrm{mg} / \mathrm{L}$. Likewise, $\mathrm{IC}_{50}$ of PMTH3E12 is slightly higher than the values reported for dodecyl gemini surfactants incorporating an heteroatom, $\mathrm{O}$ or $\mathrm{N}$, in the polymethylene spacer, 1.0 or $1.1 \mathrm{mg} / \mathrm{L}$, respectively [15]. It suggests that the increase of surfactant hydrophilicity, either by incorporating a heteroatom to the spacer or an ester functionality in the hydrophobic tails, leads to a reduction of the aquatic toxicity. When the toxicity to daphnia of dodecyl betainate trimeric surfactant PMTH3E12 (Table 3) is compared with that of the monomeric, $N$-dodecyl$N, N, N$-trimethylammonium bromide, $\mathrm{IC}_{50}=0.38 \mathrm{mg} / \mathrm{L}$ [38], the cleavable oligomeric compound results to be clearly less toxic than the corresponding non-cleavable monomeric 
surfactant. These results are consistent with findings obtained in earlier studies about the lower toxicity of dimeric surfactants as compared to monomeric ones $[15,17]$. Therefore, the use of oligomeric surfactants could result less hazardous to the aquatic compartment than the use of monomeric ones, specially bearing in mind that the higher efficiency of oligomeric surfactants with regard to monomeric ones [16,43] implies the use of lower amounts of surfactants, which is relevant from an ecological point of view.

\section{Conclusions}

New cleavable oligomeric cationic surfactants containing labile ester linkages between the hydrocarbon tails and the hydrophilic moiety and aza-substituted spacers have been synthesized. These new cationic betainate oligomeric surfactants show high percentages of biodegradation as compared to dimeric surfactants without ester groups, which exhibit null degradation under the same test conditions. Trimeric betainate surfactants exhibit higher biodegradation rates than dimeric ones, being the trimeric compound with the longest alkyl chain, PMTH3E12, the surfactant that undergoes the largest biodegradation degree. However, despite the significant increase in the biodegradation rate caused by the presence of labile ester bonds, the values attained $(<60 \%)$ are not high enough as to consider them as readily biodegradable compounds. The incomplete degradation of these eleavable-oligomeric surfactants is attributed to the resistance to biodegradation of the hydrophilic cationic moiety generated from ester bond hydrolysis. On the other hand, the introduction of a labile bond in the hydrophobic alkyl chains leads to the reduction of the surfactant toxicity to the microorganisms responsible for degradation. These new surfactants do not inhibit the degradation of readily biodegradable organic compounds by activated sludge and, therefore, it is expected that their presence in wastewater will not impair the functioning of biological 
treatment process. Acute toxicity of betainate oligomeric surfactants to Daphnia magna increases with lengthening the alkyl chains, which means that the molecule hydrophobicity governs the aquatic toxicity of these cleavable oligomeric surfactants.

This work contributes to the design and development of cationic oligomeric surfactants with better environmental properties. The introduction of potential sites of primary biodegradation in the surfactant molecule has proved to be a good approach to improve the biodegradability and reduce the aquatic toxicity of oligomeric alkylammonium surfactants.

\section{Acknowledgements}

This work was supported by National Centre for Research and Development (Poland; TANGO1/266340/NCBR/2015) and the Spanish Ministry of Economy and Competitiveness (CTQ2017-88948-P)

\section{References}

[1] B. Brycki, M. Waligórska, A. Szulc, The biodegradation of monomeric and dimeric alkylammonium surfactants, J. Hazard. Mater. 280 (2014) 797-815. doi:10.1016/j.jhazmat.2014.08.021.

[2] U. Merrettig-Bruns, E. Jelen, Anaerobic biodegradation of detergent surfactants, Materials (Basel). 2 (2009) 181-206. doi:10.3390/ma2010181.

[3] M.A. Malik, M.A. Hashim, F. Nabi, S.A. Al-Thabaiti, Z. Khan, Anti-corrosion ability of surfactants: a review, Int. J. Electrochem. Sci. 6 (2011) 1927-1948. https://umexpert.um.edu.my/file/publication/00003265_70340.pdf.

[4] W.-S. Liu, C.-H. Wang, J.-F. Sun, G.-G. Hou, Y.-P. Wang, R.-J. Qu, Synthesis, Characterization and Antibacterial Properties of Dihydroxy Quaternary Ammonium Salts with Long Chain Alkyl Bromides, Chem. Biol. Drug Des. 85 (2015) 91-97. 
doi:10.1111/cbdd.12427.

[5] N.A. Negm, I.A. Aiad, Synthesis and Characterization of Multifunctional Surfactants in Oil-Field Protection Applications, J. Surfactants Deterg. 10 (2007) 87-92. doi:10.1007/s11743-007-1016-8.

[6] U. Tezel, S.G. Pavlostathis, Quaternary ammonium disinfectants: Microbial adaptation,Degradation and ecology, Curr. Opin. Biotechnol. 33 (2015) 296-304. doi:10.1016/j.copbio.2015.03.018.

[7] X. Li, X. Luo, B. Mai, J. Liu, L. Chen, S. Lin, Occurrence of quaternary ammonium compounds (QACs) and their application as a tracer for sewage derived pollution in urban estuarine sediments, Environ. Pollut. 185 (2014) 127-133. doi:10.1016/j.envpol.2013.10.028.

[8] X. Li, B.J. Brownawell, Quaternary ammonium compounds in urban estuarine sediment environments - A class of contaminants in need of increased attention?, Environ. Sci. Technol. 44 (2010) 7561-7568. doi:10.1021/es1011669.

[9] D. Shukla, V.K. Tyagi, Cationic gemini surfactants: a review, J. Oleo Sci. 55 (2006) 381-390. doi:10.56500/jos.55.381.

[10] R. Sharma, A. Kamal, M. Abdinejad, R.K. Mahajan, H.B. Kraatz, Advances in the synthesis, molecular architectures and potential applications of gemini surfactants, Adv. Colloid Interface Sci. 248 (2017) 35-68. doi:10.1016/j.cis.2017.07.032.

[11] B.E. Brycki, I.H. Kowalczyk, A. Szulc, O. Kaczerewska, M. Pakiet, Multifunctional Gemini Surfactants: Structure, Synthesis, Properties and Applications, in: R. Najjar (Ed.), Appl. Charact. Surfactants, InTech, 2017.

[12] M.S. Kamal, A Review of Gemini Surfactants: Potential Application in Enhanced Oil Recovery, J. Surfactants Deterg. 19 (2016) 223-236. doi:10.1007/s11743-015-1776-5.

[13] A. Rodríguez, M. del M. Graciani, A.J. Moreno-Vargas, M.L. Moyá, Mixtures of 
Monomeric and Dimeric Surfactants: Hydrophobic Chain Length and Spacer Group Length Effects on Non Ideality, J. Phys. Chem. B. 112 (2008) 11942-11949. doi:10.1021/jp802243f.

[14] R. Zana, Critical Micellization Concentration of Surfactants in Aqueous Solution and Free Energy of Micellization, Langmuir. 12 (1996) 1208-1211. doi:10.1021/la950691q.

[15] M.T. Garcia, O. Kaczerewska, I. Ribosa, B. Brycki, P. Materna, M. Drgas, Biodegradability and aquatic toxicity of quaternary ammonium-based gemini surfactants: Effect of the spacer on their ecological properties, Chemosphere. 154 (2016) 155-160. doi:10.1016/j.chemosphere.2016.03.109.

[16] M.T. Garcia, O. Kaczerewska, I. Ribosa, B. Brycki, P. Materna, M. Drgas, Hydrophilicity and flexibility of the spacer as critical parameters on the aggregation behavior of long alkyl chain cationic gemini surfactants in aqueous solution, J. Mol. Liq. 230 (2017) 453-460. doi:10.1016/j.molliq.2017.01.053.

[17] O. Kaczerewska, B. Brycki, I. Ribosa, F. Comelles, M.T. Garcia, Cationic gemini surfactants containing an O-substituted spacer and hydroxyethyl moiety in the polar heads: Self-assembly, biodegradability and aquatic toxicity, J. Ind. Eng. Chem. 59 (2018) 141-148. doi:10.1016/j.jiec.2017.10.018.

[18] Z. Liang, F. Ge, H. Zeng, Y. Xu, F. Peng, M. Wong, Influence of cetyltrimethyl ammonium bromide on nutrient uptake and cell responses of Chlorella vulgaris, Aquat. Toxicol. 138-139 (2013) 81-87. doi:10.1016/j.aquatox.2013.04.010.

[19] A.R. Tehrani-Bagha, H. Oskarsson, C.G. van Ginkel, K. Holmberg, Cationic estercontaining gemini surfactants: Chemical hydrolysis and biodegradation, J. Colloid Interface Sci. 312 (2007) 444-452. doi:10.1016/j.jcis.2007.03.044.

[20] J. Aburto, I. Alric, S. Thiebaud, E. Borredon, D. Bikiaris, J. Prinos, C. Panayiotou, 
Synthesis, characterization, and biodegradability of fatty-acid esters of amylose and starch, J. Appl. Polym. Sci. 74 (1999) 1440-1451.

[21] B.V. Chang, C.M. Yang, C.H. Cheng, S.Y. Yuan, Biodegradation of phthalate esters by two bacteria strains, Chemosphere. 55 (2004) 533-538.

doi:10.1016/j.chemosphere.2003.11.057.

[22] W.G. Glasser, B.K. McCartney, G. Samaranayake, Cellulose derivatives with low degree of substitution. 3 . The biodegradability of cellulose esters using a simple enzyme assay, Biotechnol. Prog. 10 (1994) 214-219.

[23] X.-R. Xu, H.-B. Li, J.-D. Gu, Biodegradation of an endocrine-disrupting chemical di-nbutyl phthalate ester by Pseudomonas fluorescens B-1, Int. Biodeterior.

Biodegradation. 55 (2005) 9-15. doi:10.1016/j.ibiod.2004.05.005.

[24] A.R. Tehrani-Bagha, K. Holmberg, Cationic Ester-Containing Gemini Surfactants: Physical-Chemical Properties, Langmuir. 26 (2010) 9276-9282. doi:10.1021/la1001336.

[25] S. Mishra, V.K. Tyagi, Ester Quats: The Novel Class of Cationic Fabric Softeners, J. Oleo Sci. 56 (2007) 269-276. doi:10.5650/jos.56.269.

[26] I.M. Dodd, C.A. Thoen, M.A. Moss, Detergents compositions comprising a cationic ester surfactant and a grease dispensing agent, United States Pat. (1999).

[27] A.R. Tehrani-Bagha, R.G. Singh, K. Holmberg, Solubilization of two organic dyes by cationic ester-containing gemini surfactants, J. Colloid Interface Sci. 376 (2012) 112118. doi:10.1016/j.jcis.2012.02.016.

[28] J. Łuczyński, R. Frąckowiak, A. Włoch, H. Kleszczyńska, S. Witek, Gemini ester quat surfactants and their biological activity, Cell. Mol. Biol. Lett. 18 (2013). doi:10.2478/s11658-012-0041-4.

[29] B. Ee, Preparation, Surface-Active Properties and Antimicrobial Activities of Gemini 
Surfactants based on Morpholine and Piperidine, (2017) 9.

[30] N. Fatma, M. Panda, M. Beg, Ester-bonded cationic gemini surfactants: Assessment of their cytotoxicity and antimicrobial activity, J. Mol. Liq. 222 (2016) 390-394. doi:10.1016/j.molliq.2016.07.044.

[31] A.M. Atta, G.A. El-Mahdy, A.K.F. Dyab, H.A. Allohedan, Application of Highly Surface Active Cationic Surfactants Based on Rosin as Corrosion Inhibitor for Tubing Steel During Acidization of Petroleum Oil and Gas Wells, Int. J. Electrochem. Sci. 8 (2013) 15 .

[32] OECD, OECD Guidelines for Testing of Chemicals. No 310. Ready Biodegradability CO2 in Sealed Vessels (Headspace Test), 2014.

[33] OECD, OECD Guidelines for Testing of Chemicals. No 202. Daphnia sp. Acute Immobilisation Test, 2004.

[34] T. Tatsumi, W. Zhang, T. Kida, Y. Nakatsuji, Novel Hydrolyzable and Biodegradable Cationic Gemini Surfactants : 1, 3-Bis [( acyloxyalkyl ) - dimethylammonio ] -2hydroxypropane Dichloride, 3 (2000).

[35] T. Tatsumi, W. Zhang, T. Kida, Y. Nakatsuji, D. Ono, T. Takeda, I. Ikeda, Novel Hydrolyzable and Biodegradable Cationic Gemini Surfactants: Bis(ester-ammonium) Dichloride Having a Butenylene or a Butynylene Spacer, J. Surfactants Deterg. 4 (2001) 279-285. doi:10.1007/s11743-001-0180-6.

[36] A. Koziróg, B. Brycki, Monomeric and gemini surfactants as antimicrobial agents influence on environmental and reference strains, Acta Biochim. Pol. 62 (2015) 879883. doi:10.18388/abp.2015_1150.

[37] M.G. Hajaya, S.G. Pavlostathis, Fate and effect of benzalkonium chlorides in a continuous-flow biological nitrogen removal system treating poultry processing wastewater, Bioresour. Technol. 118 (2012) 73-81. 
doi:10.1016/j.biortech.2012.05.050.

[38] M.T. Garcia, E. Campos, J. Sanchez-Leal, J. Vives-Rego, Effect of the alkyl chain length on the anaerobic biodegradability and toxicity of quaternary ammonium based surfactants, Chemosphere. 39 (1999) 3473-3483.

[39] M. Lavorgna, C. Russo, B. D’Abrosca, A. Parrella, M. Isidori, Toxicity and genotoxicity of the quaternary ammonium compound benzalkonium chloride (BAC) using Daphnia magna and Ceriodaphnia dubia as model systems., Environ. Pollut. (Oxford, United Kingdom). 210 (2016) 34-39. doi:10.1016/j.envpol.2015.11.042.

[40] M.T. Garcia, E. Campos, A. Marsal, I. Ribosa, Biodegradability and toxicity of sulfonate-based surfactants in aerobic and anaerobic aquatic environments., Water Res. 43 (2009) 295-302. doi:10.1016/j.watres.2008.10.016.

[41] M.T. Garcia, E. Campos, A. Marsal, I. Ribosa, Fate and effects of amphoteric surfactants in the aquatic environment, Environ. Int. 34 (2008) 1001-1005. doi:10.1016/j.envint.2008.03.010.

[42] OECD, OECD Harmonised integrated classification system for human health and environmental hazards of chemical substances and mixtures. Series on Testing and Assessment, No 33, ENV/JM/MONO, 2001.

[43] N.A. Negm, A.M. Al Sabagh, M.A. Migahed, H.M.A. Bary, H.M. El Din, Effectiveness of some diquaternary ammonium surfactants as corrosion inhibitors for carbon steel in $0.5 \mathrm{M} \mathrm{HCl}$ solution, Corros. Sci. 52 (2010) 2122-2132. doi:10.1016/j.corsci.2010.02.044. 